\title{
Brown Fat Activity Determined by Infrared Thermography and Thermogenesis Measurement Using Whole Body Calorimetry (BRIGHT Study)
}

\author{
Shi Huan TAY ${ }^{1}$, Hui Jen GOH ${ }^{1}$, Priya GOVINDHARAJULU ${ }^{1}$, Jierong CHENG ${ }^{2}$, Stefan \\ Gerardus Joseph Anna CAMPS ${ }^{1}$, Sumanto HALDAR ${ }^{1}$, Sambasivam Sendhil VELAN ${ }^{3,4}$, Lei \\ SUN $^{5}$, Yiqun LI ${ }^{2}$, Christiani Jeyakumar HENRY ${ }^{1,6}$, Melvin Khee-Shing LEOW ${ }^{1,5,7,8,9}$ \\ ${ }^{1}$ Clinical Nutrition Research Centre, Singapore Institute for Clinical Sciences, Agency for Science, \\ Technology and Research (A*STAR), Singapore, ${ }^{2}$ Institute for Infocomm Research, Agency for \\ Science, Technology and Research (A*STAR), Singapore, ${ }^{3}$ Laboratory of Molecular Imaging, \\ Singapore Bioimaging Consortium, Agency for Science, Technology and Research (A*STAR), \\ Singapore, ${ }^{4}$ Department of Medicine and Physiology, Yong Loo Lin School of Medicine, National \\ University of Singapore, Singapore, ${ }^{5}$ Cardiovascular and Metabolic Disorders Program, Duke-NUS \\ Medical School, Singapore, ${ }^{6}$ Department of Biochemistry, Yong Loo Lin School of Medicine, \\ National University of Singapore, Singapore, ${ }^{7}$ Department of Endocrinology, Tan Tock Seng \\ Hospital, Singapore, ${ }^{8}$ Department of Medicine, Yong Loo Lin School of Medicine, National \\ University of Singapore, Singapore, ${ }^{9}$ Lee Kong Chian School of Medicine, Nanyang Technological \\ University, Singapore
}

Received April 14, 2019

Accepted September 25, 2019

Epub Ahead of Print December 19, 2019

\section{Summary}

To assess BAT activity in humans at a population level, infrared thermography (IRT) represents a safe, readily repeatable and affordable alternative to ${ }^{18} \mathrm{~F}$-FDG-PET. Building upon a previously proposed method by our laboratory, we further refined the image computational algorithm to quantify BAT activation in the cervical-supraclavicular (C-SCV) region of healthy young men under thermo-neutral and cold exposure conditions. Additionally, we validated the whole-body calorimeter (WBC) in reliably measuring cold-induced thermogenesis. The temperature gradient between C-SCV-deltoid regions, and the corresponding difference in heat power output, increased upon cold air exposure relative to thermo-neutral conditions (by $74.88 \%$, $\mathrm{p}<0.0001$; and by $71.34 \%, \mathrm{p}<0.0001$ respectively). Resting and cumulative energy expenditure (EE) rose significantly (by $13.14 \%$ and $9.12 \%$ respectively, $p=0.0001$ ) while positive correlations between IRT measures and EE were found with cold air exposure (percentage change in heat power gradient between ROI and deltoid, cold air: $r^{2}=0.29, p=0.026$, Pearson's correlation). IRT and WBC can be used to study BAT activation.
The refined algorithm allows for more automation and objectivity in IRT data analysis, especially under cold air exposures.

\section{Key words}

Brown adipose tissue - Infrared thermography • Calorimetry • Thermogenesis • Automation

\section{Corresponding author}

S. H. Tay, Clinical Nutrition Research Centre, Singapore Institute for Clinical Sciences, Agency for Science, Technology and Research (A*STAR), Singapore. E-mail: tay_shi_huan@u.duke.nus.edu

\section{Introduction}

The global obesity epidemic represents a rapidly escalating threat to public health. The underlying basis common to the plethora of causes and pathways of overweight and obesity is chronic excessive positive energy balance (i.e. energy intake>energy expenditure). 
Unfortunately, the modern obesogenic environment promotes overweight and obesity, and poor adherence to lifestyle interventions aimed at correcting the energy imbalance (e.g. eating in moderate amounts and exercising frequently) further compounds this burgeoning problem. This ultimately leads to significant morbidity and mortality, including atherosclerosis and increased susceptibility to infections (Hainer et al. 2015, Pitha et al. 2015). As such, it is imperative to explore novel strategies for attenuating obesity.

Adipose tissue have complex roles in energy balance; white adipose tissue (WAT) functions as an energy store, while brown adipose tissue (BAT) dissipates energy in the form of heat (Gesta et al. 2007). BAT includes both classical brown adipocytes as well as beige/brite adipocytes (Ishibashi and Seale 2010, Petrovic et al. 2010, Vegiopoulos et al. 2010, Waldén et al. 2012 Zhang et al. 2018). The thermogenic capacity of BAT is predominantly mediated by the activity of uncoupling protein-1 (UCP1) which resides in the inner mitochondrial membrane. When activated, UCP1 initiates a futile cycle of proton pump and leak that uncouples oxidative phosphorylation and results in thermogenesis (Cannon and Nedergaard 2004, Lowell and Spiegelman 2000).

With the establishment of the existence of functional BAT in healthy adults (Cypess et al. 2009, Saito et al. 2009, van Marken Lichtenbelt et al. 2009, Virtanen et al. 2009), the exciting prospect of manipulating BAT for obesity management becomes tenable. Through the use of ${ }^{18} \mathrm{~F}$-fluoro-2-deoxy-d-glucose $\left({ }^{18} \mathrm{~F}-\mathrm{FDG}\right)$ positron emission tomography-computed tomography (PET/CT) imaging in healthy adults, substantial BAT depots have been found to be distributed over many sites in the body, with the cervicalsupraclavicular (C-SCV) region being the largest and most metabolically active (Sacks and Symonds 2013). Given that BAT activity in adult humans may be stimulated by various endogenous or external stimuli such as cold exposure (Greenhill 2013) and capsaicin/capsinoid consumption (Ang et al. 2016, Masuda et al. 2003, Saito and Yoneshiro 2013), there has hence been much interest in developing environmental, dietary and pharmacological interventions to augment BAT volume and/or activity for increasing energy expenditure.

To measure BAT volume and/or activation at a population level, non-invasive, safe, objective, repeatable and reproducible assessments of BAT activity are crucial for determining whether adipose tissue thermogenic capacity has been altered by various interventions in clinical research settings. The current "gold standard" of ${ }^{18}$ F-FDG PET/CT imaging is costly, and involves substantial ionizing radiation that is undesirable for repeated measures especially among healthy volunteers in prospective intervention studies. Moreover, instant visualization of BAT metabolic activity is limited by the inability to perform serial scans over a short period of time. Other imaging modalities such as functional magnetic resonance imaging (fMRI) techniques (Chen et al. 2012, Hu et al. 2013, Lau et al. 2014) and ultrasound (Clerte et al. 2013, Flynn et al. 2015) have the advantage of being ionizing radiation free to permit continuous real-time imaging, yet they hinge upon the tenuous assumption that BAT activity can be reliably measured from circulating substrate uptake or blood flow. Given that heat is a specific end-product of UCP-1 dependent thermogenesis, its detection via infrared thermography (IRT) at BAT specific regions thus represents a potential surrogate marker for BAT activity. Furthermore, IRT constitutes a non-invasive, painless and low-cost technique that can be effectively employed within the clinical research setting for rapid acquisitions of thermal images or videos.

IRT is an accepted technique to assess BAT activity in mice (Carter et al. 2011, Crane et al. 2014). Recent studies in humans have also validated the use of IRT with PET/CT images, whereby both modalities displayed significant concordance in monitoring BAT activity before and after cold exposure (Jang et al. 2014, Salem et al. 2016, Symonds et al. 2012). Of note, Law et al. (2018) demonstrated conclusively the positive correlation between IRT-identified supraclavicular (SCV) hotspot and the area of maximal uptake on PET-CTderived metabolic rate of glucose uptake maximumintensity-projection (MR(gluc $)_{\mathrm{MIP}}$ ) images, complemented by greater increases in relative SCV temperature with greater glucose uptake (Law et al. 2018). Nevertheless, there still exists some incongruencies in infrared (IR) image processing; for instance, there are varying methods with which the region of interest (ROI) corresponding to a potential BAT depot is identified and the manner whereby temperature values are reported - e.g. mean of entire ROI (Ang et al. 2016) versus mean of upper $10^{\text {th }}$ percentile of temperatures in ROI (Symonds et al. 2012, Law et al. 2018).

This study therefore refines an algorithm to analyze thermal images capturing BAT activity under 
cold air exposure. In addition, this study also aims to validate the sensitivity of the whole-body calorimeter (WBC) in measuring cold-induced thermogenesis, and to subsequently correlate IRT and WBC measurements for determining BAT activity under cold air exposure. The cold air exposure was aimed to represent a realistic cold experience that free-living humans can go through, such that this cooling protocol can be used to better model the effects of BAT activation following environmental and pharmacological interventions.

\section{Materials and Methods}

\section{Ethics approval and consent to participate}

Written informed consent was obtained from all subjects before enrolment in the study. This research project, acronymed the 'BRIGHT Study', was approved by the National Healthcare Group Domain Specific
Review Board, Singapore (DSRB approval reference: C/2014/00721), registered with ClinicalTrials.gov (NCT02790255) and performed in accordance with the Declaration of Helsinki.

\section{Subjects}

A total of 17 healthy Chinese males (age $24 \pm 0.52$ years, BMI $21.7 \pm 0.63 \mathrm{~kg} / \mathrm{m}^{2}$ ) were recruited (Table 1), following a screening session consisting of a health questionnaire as well as measurements of BMI and fasting blood glucose levels. Exclusion criteria included smoking, training for and participating in competitive sports for the past 6 months, regular medication and major medical conditions including cardiovascular disease and diabetes. Females were excluded from the study to minimize variability that may arise from menstrual cycle effects.

Table 1. Baseline characteristics of subjects.

\begin{tabular}{|c|c|}
\hline Characteristics & Mean $( \pm$ S.E. $)$ \\
\hline Males (n) & 17 \\
\hline Age (years) & $24 \pm 0.52$ \\
\hline Body weight (kg) & $64.7 \pm 1.30$ \\
\hline Height (m) & $1.73 \pm 0.018$ \\
\hline$B M I\left(k g / m^{2}\right)$ & $21.7 \pm 0.63$ \\
\hline Total fat mass ( $\mathrm{kg})$ & $20.8 \pm 0.81$ \\
\hline Body fat $(\%)$ & $13.4 \pm 0.64$ \\
\hline Fasting blood glucose (mmol/l) & $4.6 \pm 0.09$ \\
\hline Resting heart rate (b.p.m.) & $72 \pm 2.71$ \\
\hline Systolic BP (mm Hg) & $125 \pm 2.78$ \\
\hline Diastolic BP ( $\mathrm{mm} \mathrm{Hg})$ & $71 \pm 2.10$ \\
\hline RMR (kcal/day) & $1482 \pm 31.72$ \\
\hline Resting $R Q$ & $0.82 \pm 0.03$ \\
\hline$B M D\left(\mathrm{~g} / \mathrm{cm}^{2}\right)$ & $1.16 \pm 0.02$ \\
\hline
\end{tabular}

Abbreviations: BMI, body mass index; $\mathrm{BP}$, blood pressure; RMR, resting metabolic rate; RQ, respiratory quotient; $\mathrm{BMD}$, bone mineral density. Results are expressed as mean \pm S.E.

\section{Body composition}

Body composition including bone mineral density (BMD), total fat mass and body fat percentage was measured by dual-energy X-ray absorptiometry (Hologic Discovery Wi, APEX Software version 4.0.1, USA). BMI was calculated as the body weight in kilograms divided by the square of the height in meters $\left(\mathrm{kg} / \mathrm{m}^{2}\right)$.
Study visit

Subjects were exposed to cold air of $18 \pm 2{ }^{\circ} \mathrm{C}$ and compared against thermo-neutral ambient temperature $\left(24 \pm 1^{\circ} \mathrm{C}\right)$. The experiments were entirely conducted inside the dual chamber whole-body calorimeter (WBC) (Omnical, Maastricht Instruments BV, Maastricht, Netherlands) that was furnished with features typical of a normal room, with windows at sides 
of the chamber that allow experimenters to visually monitor the subjects for shivering and any other movements. Being hermetically sealed, the calorimeter allows for precise interior climate control of ambient temperature and humidity, as well as accurate measurements of energy expenditure.

Subjects spent 45 minutes in the WBC 1 under a thermo-neutral ambient temperature of $24 \pm 1{ }^{\circ} \mathrm{C}$ (as per Singapore's tropical rainforest climate - Köppen climate classification Af). Following this thermo-neutral period, they were exposed to cold air in the adjoining chamber WBC 2. Shivering was neither observed by the experimenter nor reported by the subjects during cold exposure.

This involved 45 min in WBC 2 programmed to an ambient temperature of $18 \pm 2{ }^{\circ} \mathrm{C}$. IR imaging of the $\mathrm{C}-\mathrm{SCV}$ and deltoid regions was performed at 2.5-min intervals for $2 \times 45$ min over both the thermo-neutral and cold exposure conditions for each study session (Fig. 1). The skin over the deltoid was selected as a negative control as it is known to be devoid of BAT. A temperature gradient between the ROI and the deltoid was subsequently calculated, which better captures the differential heat production in BAT-positive versus BAT-negative regions under global skin cooling.

Prior to the study visit, subjects fasted and drank only plain water from 22:00 $\mathrm{h}$ the evening before. In addition, they abstained from caffeine, alcohol and strenuous exercise $24 \mathrm{~h}$ prior to testing. Upon arrival between 08:00 $\mathrm{h}$ and 09:00 $\mathrm{h}$ on the day of testing, subjects changed into the standardized testing attire of cotton singlet and Bermuda shorts, which has an estimated clo value of 0.2 (Hoyte et al. 2013). The clo unit provides a measure of thermal insulation provided by clothing (Gagge et al. 1941). The choice of attire ensures adequate exposure of the neck and upper thorax for thermal imaging. A peripheral venous cannula was inserted at the antecubital fossa of the forearm for blood sampling.

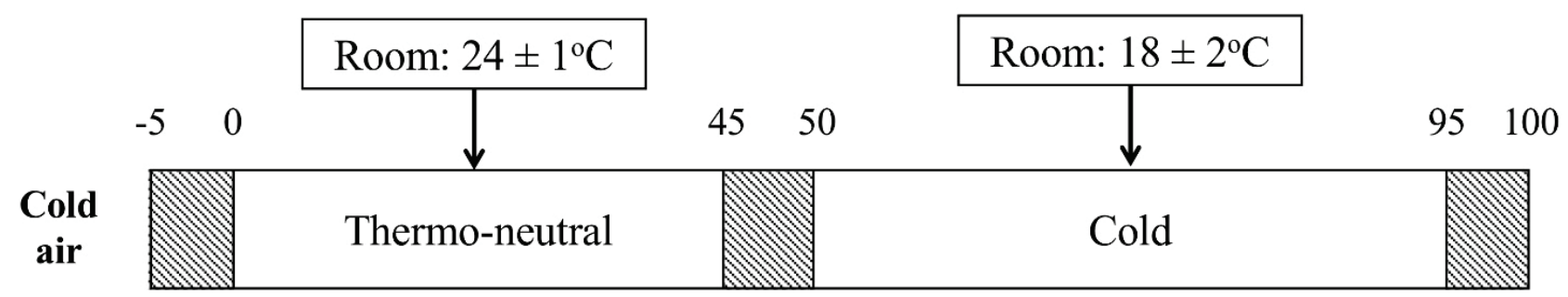

Fig. 1. The unshaded areas correspond to periods when non-shivering thermogenesis was assessed, with IR imaging of the C-SCV regions being performed at 2.5-min intervals (1-second long videos, 30 frames per second) and concurrent measurement of EE by the WBC. The shaded areas correspond to periods when blood samples were drawn ( 3 in total for each study session). The numbers represent time elapsed in minutes.

\section{Infrared thermography (IRT) imaging}

Subjects were seated in an upright posture on an armchair, with head positioned in a neutral position and arms adducted. A thermal imaging camera (FLIR T440, FLIR Systems, Sweden; sensor array size $320 \mathrm{x}$ 240 pixels, noise equivalent temperature difference $($ NETD $)<45 \mathrm{mK}$ ) was mounted on a tripod, placed on the left of the subject and positioned at the neck level $1 \mathrm{~m}$ away from the subject's face. The subject is seated in a neutral position and the camera's optical axis makes an angle of 45 degrees with the subject's line of vision in the horizontal plane, with the camera slightly below eye level and focused on the subject's left C-SCV region. All IRT video recordings were acquired over a standard recording period of $1 \mathrm{~s}$ (at a rate of 30 frames per second), whereby anterolateral views of the left C-SCV region as well as the upper section of the left deltoid were captured. Subjects were requested to remain as still as possible, with their shoulders unrotated against the back of the chair to minimize movement within the image frames during thermal video recordings.

\section{Whole-body calorimetry (WBC)}

Measurements of energy expenditure (EE; $\mathrm{kcal} / \mathrm{min}$ ) and respiratory quotient (RQ) throughout the study sessions were conducted in the dual room WBC. They were performed in conjunction with IRT under both the thermo-neutral $\left(24 \pm 1^{\circ} \mathrm{C}\right)$ and cold $\left(18 \pm 2{ }^{\circ} \mathrm{C}\right)$ exposure conditions.

EE was measured using the principle of indirect calorimetry through gaseous exchanges in the open circuit air-tight WBC chambers (Goh et al. 2016). Prior 
to the study visit, both WBC chambers were calibrated against standard calibration span gases. During a study visit, both oxygen consumption and carbon dioxide production were measured continuously via inlet \& outlet differences, under standard temperature, pressure and dry (STPD) (Goh et al. 2016). The accuracy of the WBC chambers was regularly assessed via complete combustion of a known quantity of methanol, and reported by Henry et al. (2017): $\mathrm{O}_{2}=100.6 \pm$ $0.5 \%$ (chamber 1) and $100.9 \pm 0.4 \%$ (chamber 2), $\mathrm{CO}_{2}=99.2 \pm 0.5 \%$ (chamber 1) and $99.7 \pm 0.5 \%$ (chamber $2)$, and coefficient of variation $=3.0 \%(n=21)$ for repeated 30-minute resting metabolic rate (RMR) measurements with the WBC chambers (Henry et al. 2017).

\section{Infrared video analysis}

Thermal data was initially recorded in a radiometric infrared video format, and was exported into avi and .csv files using the FLIR ResearchIR Software (Version 3.3, Wilsonville, OR, USA). Using MATLAB (R2013a), an in-house algorithm was developed to detect local ROIs (Ang et al. 2016), which in this study refer to the hot regions overlaying potential left C-SCV BAT depots (Fig. 2A). This algorithm employs a modified Seeded Region Growing (SRG) technique for its purpose (Fig. 2B).

At the start of the algorithm, a bounding box encompassing likely C-SCV BAT depots is manually drawn on the first frame of the IR video, from which the pixel of the highest temperature value $T_{\max }$ is automatically selected as a "seed". The same bounding box is used on the remaining frames, based on the assumption that the subject kept still over video acquisition such that the "seed" always falls within the box.

The seed initializes the ROI, which is iteratively grown by comparing all unallocated neighboring pixels to the region. The difference between a pixel's intensity/temperature value and the region's mean is used as a measure of similarity, such that adjoining pixels with high similarity will be allocated to the region until the intensity difference between the region's mean and the temperature value of the new pixel exceeds a threshold $T_{t}$. In our study, $T_{t}$ was adjusted manually for individual subjects to achieve reliable segmentation. ROIs from all frames are obtained via this process.

In the second part of the algorithm, all frames in a single IR video are calibrated by detecting and utilizing circular aluminum foil disks that were placed on the subject's skin (diameter of $5 \mathrm{~mm} ; 4$ on the face and 1 on the upper section of the deltoid, about $2 \mathrm{~cm}$ below the lateral border of the acromion). Morphological opening is applied to every frame to enhance circular objects, which facilitates the identification of the aluminum markers as regional minima via the H-minima transform. The H-minima transform suppresses all minima in the intensity image whose depth is less than a pre-set threshold $h$ to sieve out potential candidates (Soille 1999), and a roundness metric is computed for each candidate as follows:

$$
\text { Metric }=4 * \pi * a / p^{2},
$$

Where $a$ and $p$ are its area and perimeter respectively. The candidates with highest metric values/roundness correspond to the aluminum markers. Following marker identification on every frame, the center of the 4 facial markers (i.e. the intersection point of both diagonals within the square formed by the facial markers) is used to align all frames in the IR video. The subsequent mathematical set union of every frame's ROI produces an overall ROI for the particular time-point at which the video was taken. The pixel count of the overall ROI is provided by the algorithm, and it can be used to estimate the actual area of the hot region overlaying the potential left C-SCV BAT depots.

Subsequently, the algorithm calculates the mean temperature of the pixels and the heat power output of the overall ROI. Frame averaging is first performed across the aligned frames of the entire video to augment signalto-noise ratio, following which the overall ROI is superimposed over the averaged image for derivation of the ROI's mean temperature. The algorithm subsequently quantifies heat power output in watts (W) by implementing a modified Stefan-Boltzmann law (Ang et al. 2016):

BAT heat power output $=\varepsilon * \sigma * r * A * T^{4}$,

Whereby $\varepsilon$ refers to emissivity ( 0.98 for human skin), $\sigma$ is the Stefan-Boltzmann constant (5.676 $\mathrm{x}$ $\left.10^{-8} \mathrm{~W} / \mathrm{m}^{2} \mathrm{~K}^{4}\right), r$ defines the pixel-to-meter conversion factor that is computed from the area enclosed by the 4 facial markers (which demarcates a $5 \mathrm{~cm}$ by $5 \mathrm{~cm}$ square), $A$ is the area of the overall ROI in pixels and $T$ refers to the mean ROI absolute temperature in Kelvin (K). 


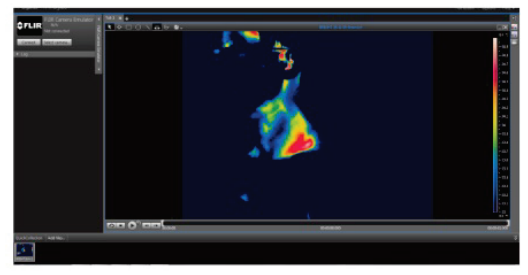

Step 1:

IR videos processed using FLIR

ResearchIR software (Ver. 3.3) to obtain $. \operatorname{csv}+$.avi files

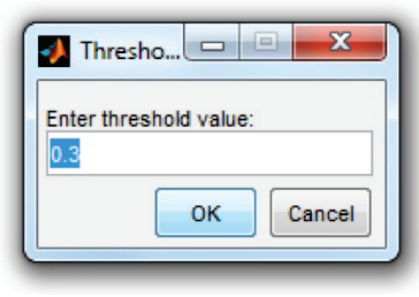

Step 3:

- User heuristically defines threshold value for segmentation

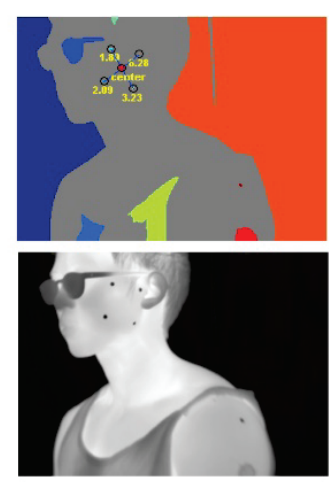

Step 5:

All frames calibrated using fiducial markers on face (detected via morphological opening and H-minima transform)

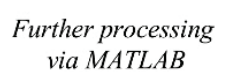
functions

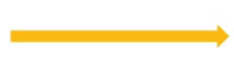

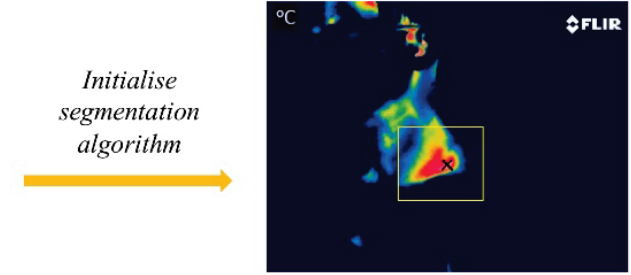

Step 2:

- User defines bounding box from which $\mathrm{T}_{\max }$ (black cross) is to be automatically identified*

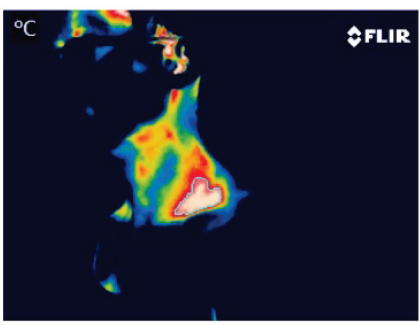

Step 4

ROI automatically segmented via Seeded Region Growing technique for every frame ( $T_{\max }$ used as seed)

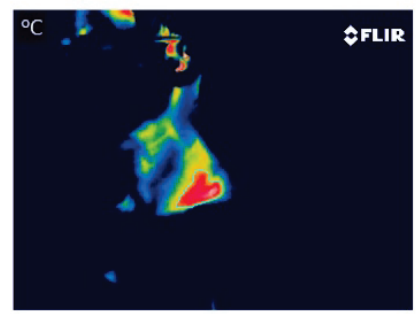

Step 6:

Summarized ROI for time-point produced by union of ROIs from every frame; superimposed on output of frame averaging

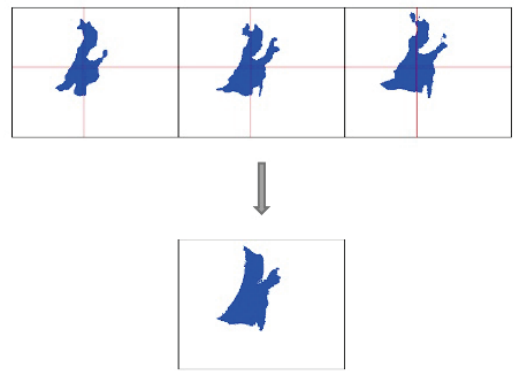

Step 7:

- Overall ROI for entire time-series produced by union of ROIs from every time-point (calibrated, maximized, refined); ROI temp., area and heat power output computed

Fig. 2A. Schematic representation of analysis of IR data. Note that Step 2 is performed on the $1^{\text {st }}$ frame, and the same bounding box is used for subsequent frames for $T_{\max }$ determination. This relies on the assumption that the subject does not move significantly in 1 s, such that bounding box will always encompass likely C-SCV BAT depots. 


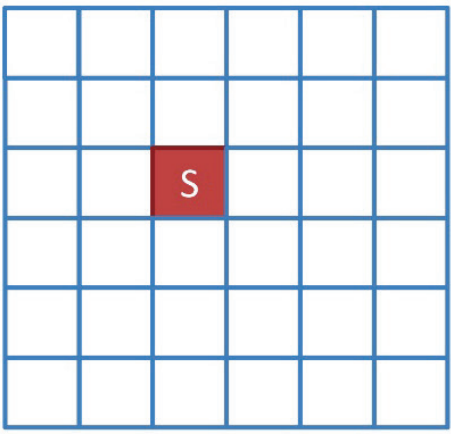

Step 0

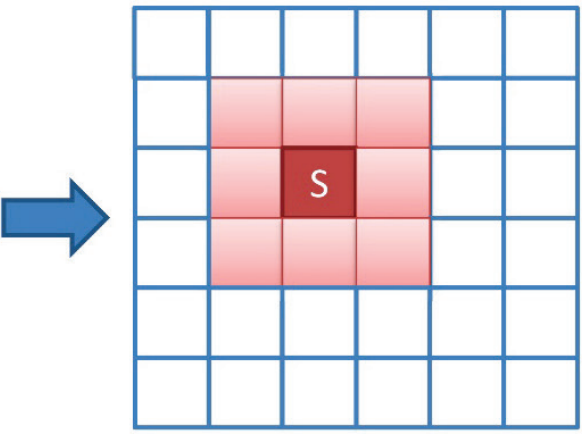

Step $1 \& 2$ (iterative)

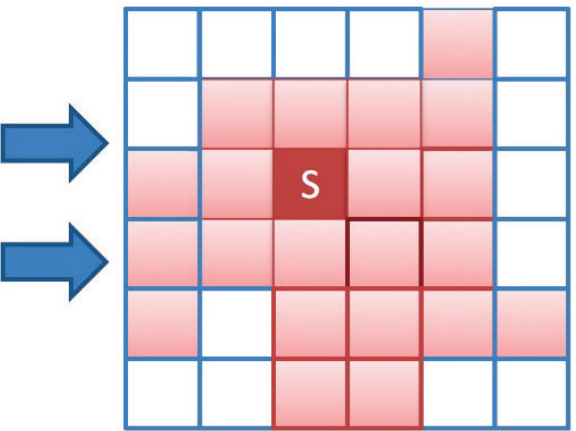

Step 3

Fig. 2B. Schematic representation of the SRG algorithm. In Step 0, the seed S is selected (via a bounding box - not shown in this diagram). The ROI is then expanded further by computing the temperature difference between the seed and its adjoining pixel, and by only accepting the adjoining pixel when the temperature difference is within a pre-defined threshold value (Steps 1 and 2). This iterative operation is repeated until the temperature difference exceeds the threshold value, with which a ROI of spatially connected pixels of similar temperature values representative of the BAT depot is derived (Step 3).

ROIs from different time-points may be calibrated using the aforementioned principle involving the fiducial markers. Next, the set union of all aligned ROIs produces a maximized ROI that is further refined via thresholding, whereby only pixels whose temperature values are within the pre-determined range will be included. The temperature range (reported in degrees Celsius $\left.\left[{ }^{\circ} \mathrm{C}\right]\right)$ is defined as:

$$
x \geq 33
$$

Where $x$ refers to the temperature value of a pixel in the maximized ROI. The lower limit is set at $33{ }^{\circ} \mathrm{C}$ to eliminate background pixels, if any, arising from noise or non-BAT regions picked up in the maximized ROI such as zones overlaid by the cotton singlet.

In this study, a maximized, refined ROI specific to each study visit was defined on a subject-by-subject basis from which downstream assessments of BAT volume and activation were conducted. The ROI was determined using the aforementioned workflow on data from the cold challenge, following which the same ROI is superimposed on data from the corresponding thermoneutral phase via the fiducial markers. This permits a direct comparison of the heat output of a subject's C-SCV BAT depot without variation introduced by incongruences in segmented area.

\section{Statistical analyses}

Statistical analysis was carried out with the SPSS software package (version 23.0; SPSS, Chicago, IL, USA). Due to a non-Gaussian distribution, the Wilcoxon matched pairs signed-rank test was used to determine if there were any differences in $\mathrm{C}-\mathrm{SCV}$ heat production under cold exposure relative to thermo-neutral conditions. For correlations between measures of BAT activity and various parameters of interest, normality was first evaluated with the Shapiro-Wilk test before using the Pearson's correlation and Spearman's rho correlation for appropriate datasets. Data were expressed as mean \pm standard deviation (S.D.) or standard error (S.E.) wherever appropriate, and the significance level of all tests was set at $5 \%$.

\section{Results}

IRT quantification of cold-stimulated heat production in the C-SCV region

The final 10-min period of cold air exposure ( $\mathrm{t}=35 \mathrm{~min}$ to $45 \mathrm{~min}$ ) was used for analysis of IRT data. The cold exposure condition was then compared to the preceding isochronal thermo-neutral stages. Mean deltoid temperature fell to a greater extent than mean ROI temperature ( $10.32 \%$ vs. $1.71 \%$ respectively, $p<0.0001)$. Consequently, the temperature gradient between ROI and deltoid, as well as the corresponding difference in heat power output computed, increased upon cold exposure relative to thermo-neutral conditions (Table 2).

Effect of cold exposure on WBC-quantified EE and IRT-EE correlations in cold air exposure

The resting EE increased during cold air exposure by $201 \mathrm{kcal} /$ day as compared to baseline, thermo-neutral conditions ( $13.14 \%$ rise, $p<0.0001$; Table 2). Similarly, the cumulative EE increased during cold air exposure by $4.46 \mathrm{kcal}(9.12 \%$ increase over BMR, $p<0.0001$; Table 2).

The percentage changes in temperature gradient 
between ROI and deltoid $\left(\mathrm{r}^{2}=0.27, p=0.031\right.$, Pearson's correlation) as well as in heat power gradient between ROI and deltoid $\left(\mathrm{r}^{2}=0.29, p=0.026\right.$, Pearson's correlation; Fig. 3) displayed modest positive correlations with that in
EE. This thereby suggests that a greater increase in total energy expended upon cold air exposure may be contributed by an increase in BAT activity as measured by IRT.

Table 2. Changes in temperature and heat power output of ROI and deltoid, as well as in resting and cumulative EE during cold air exposure.

\begin{tabular}{lccc}
\hline Variables & Before & After & Percentage change (\%) \\
\hline $\begin{array}{l}\text { Cold air challenge } \\
\text { Mean ROI temperature }\left({ }^{\circ} \mathrm{C}\right)\end{array}$ & $34.99 \pm 0.36$ & $34.39 \pm 0.48$ & $-1.71^{*}$ \\
Mean deltoid temperature $\left({ }^{\circ} \mathrm{C}\right)$ & $31.44 \pm 0.44$ & $28.19 \pm 0.73$ & $-10.32^{*}$ \\
Temperature gradient between & $3.55 \pm 0.46$ & $6.20 \pm 0.80$ & $74.88^{*}$ \\
ROI and deltoid $\left({ }^{\circ} \mathrm{C}\right)$ & & & $71.34^{*}$ \\
Heat power gradient between & $0.0625 \pm 0.018$ & $0.107 \pm 0.03$ & $13.14^{*}$ \\
ROI and deltoid $(\mathrm{W})$ & $1486 \pm 144$ & $1687 \pm 274$ & $9.12^{*}$ \\
Resting EE $($ kcal/day) & $48.9 \pm 4.4$ & $53.4 \pm 7.7$ & \\
Cumulative EE $($ kcal $)$ & & & \\
\hline
\end{tabular}

${ }^{*}$ Significant difference at $p<0.0001$ (Wilcoxon matched pairs signed-rank test) between cold exposure and thermo-neutral conditions. Values are presented as the mean ( \pm S.D.). ROI heat power is calculated based on the Stefan-Boltzmann law, using the refined, maximized ROI on a subject- and study visit-specific basis.

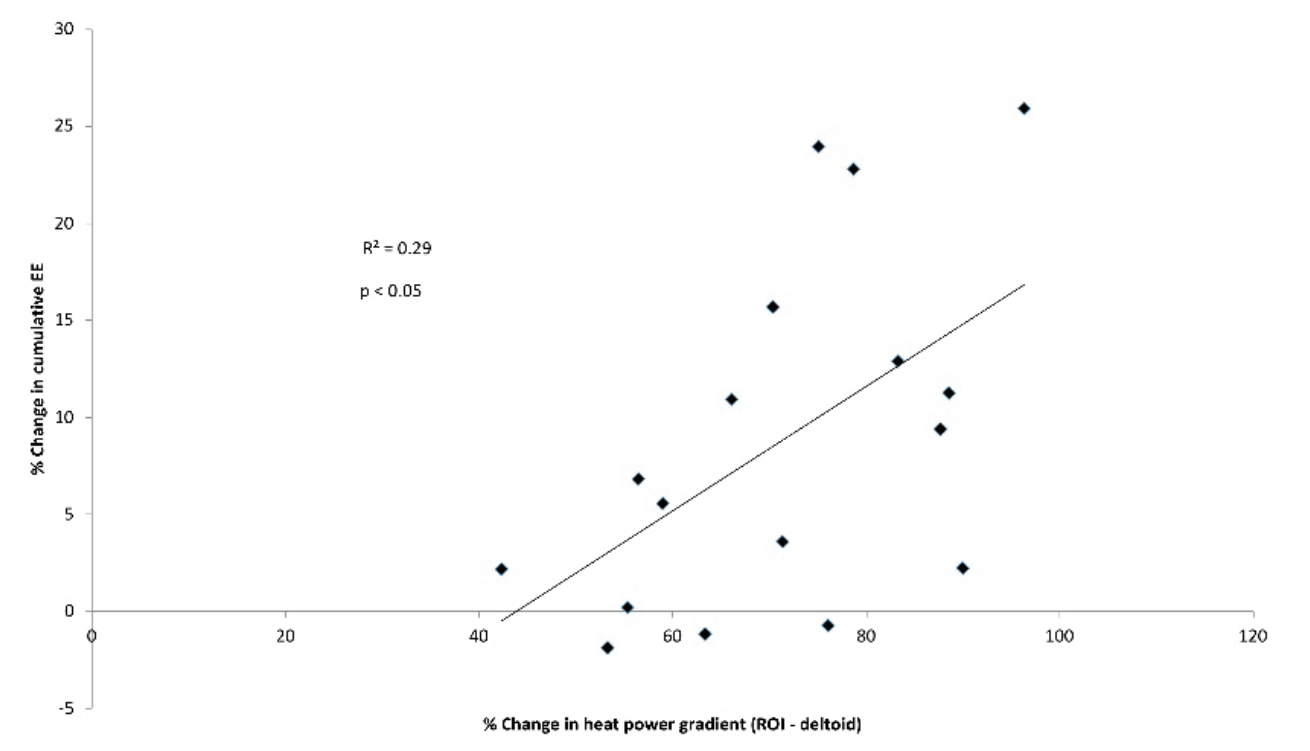

Fig. 3. Correlation between percen-tage change in heat power gradient between ROI and deltoid and that in cumulative EE (cold air exposure).

\section{Discussion}

The purpose of this study is to further explore the use of IRT in quantifying BAT activity, by modifying a method previously proposed by our laboratory (Ang et al. 2016). The image segmentation method was modified and optimized to permit automated detection of the "seed" pixel after defining the bounding box encompassing likely C-SCV BAT depots on the video frames. This reduces operator dependence and introduces greater automation, thereby removing the need to arbitrarily plant the "seed" solely based on heuristics.

The use of MATLAB to generate a maximized, refined ROI on a subject- and study session-specific basis helps to reduce error in calculating ROI heat power output. A Monte Carlo simulation was performed to determine the sources of error in the measurement of heat power output using the Stefan-Boltzmann equation (Suppl. Fig. 1). Given that area is most likely the primary contributor of error in ROIs with small areas, keeping the 
ROI area constant under the assumption that the maximized, refined area demarcates maximal BAT area in the C-SCV region, will most likely to improve signalto-noise ratio.

In addition, to better analyze IRT data collected over cold air exposure to ascertain potential BAT activation, MATLAB functions were also employed to define the thermal activity of the deltoid. The skin temperature over the $\mathrm{C}-\mathrm{SCV}$ region is an indirect marker of BAT activity during cold exposure, while the BAT-devoid deltoid can be taken as a proxy of peripheral vasoconstriction (Boon et al. 2014, Chondronikola et al. 2016, van der Lans et al. 2016, Lee et al. 2011). Subsequent computations of temperature between ROI and deltoid revealed the contribution of BAT activation to the maintenance of a relatively constant temperature of skin overlaying the BAT depots during cold air exposure unlike non-BAT areas which exhibited a marked decrease in skin temperature, which thus translated to a large increase of $71.34 \%$ in the heat power gradient between the two regions. In conjunction with a $13.14 \%$ rise in resting $\mathrm{EE}$ and corresponding positive correlations between IRT and WBC measurements, it is thus plausible that BAT contributed to non-shivering thermogenesis in the subjects.

This study also reviewed the potential of the WBC to reliably capture changes in EE during BAT activation, which is shown by the expected increase in resting and cumulative EE under cold air exposure. Similar increases were also reported in prior literature on cold-induced thermogenesis in lean subjects measured by indirect calorimetry, such as a $13.7 \%$ rise following two hours of cold exposure $\left(16^{\circ} \mathrm{C}\right.$ air) captured by a respiratory gas analyzer with the use of a ventilated hood system (van Marken Lichtenbelt et al. 2009). The advantage of a room calorimeter lies in the ability to mimic free-living conditions in a controlled environment - this sets the stage for future prospective BAT studies to investigate how novel nutriceuticals and pharmaceuticals as well as human behaviour (e.g. food, physical activity) influence BAT activity in a physiological setting.

There are several limitations to this study. Despite having refined the SRG algorithm to permit more automation in IRT image processing, the threshold parameter for the segmentation algorithm still had to be manually optimized for each subject since any single preset threshold was not successful in reliably segmenting all subjects. As such, future work will demand the definition of a suitable range of threshold values that is applicable to the general population for further automation. The thickness of subcutaneous adipose tissue is thought to confound heat transfer from underlying BAT depots to skin (Gatidis et al. 2016), which may underestimate actual BAT heat power output. However, all 17 subjects were relatively lean with body fat levels below the Singaporean mean (Bi et al. 2018).

Shivering was not quantitatively measured via the use of electromyograms (EMGs) to determine the extent of shivering thermogenesis following cold exposure. However, none of the subjects had any subjective report of shivering when directly questioned nor was there any overt shivering observed by the experimenter. The use of such a shivering threshold and its acceptance as a valid method to maximize nonshivering thermogenesis and activate BAT lends further credence to our justification that our subjects did not exhibit significant shivering thermogenesis (Boon et al. 2014, Cypess et al. 2014). In addition, our results are in line with those reported in two similarly designed studies by Haq et al. (2017) and Acosta et al. (2018), who were able to exclude shivering via subjective reporting as well as surface EMG by the lack of burst activity/superficial muscle activity over the entire cooling period, thereby conclusively demonstrating that the increases in SCV temperature and energy expenditure were most likely from BAT-induced non-shivering thermogenesis (Acosta et al. 2018, Haq et al. 2017). It has been proposed that shivering thermogenesis is the last cold-defense mechanism to be activated as its thermal threshold is at a lower core temperature than that for either cutaneous vasoconstriction or BAT thermogenesis, which supports the notion that BAT thermogenesis can be and is rapidly elicited in response to cold stress (Morrison 2016). While shivering is essential in the thermoregulatory response to an intense cold stimulus, it should be appreciated that thermogenic shivering is an ancillary function of skeletal muscles that are normally used to produce movement and posture. On the other hand, non-shivering or adaptive thermogenesis in BAT is the specific metabolic function of this tissue, and BAT activation in mild cold exposure would thus be physiologically relevant (Boon and van Marken Lichtenbelt 2016).

The WBC is largely conducive for detecting EE changes during cold-induced thermogenesis, but a shortfall is that it does not allow for a rapid alteration of ambient temperature. As such, we were unable to implement an individualized cooling protocol for the cold air challenge, which would have been preferred given the 
variation in cold tolerance amongst different individuals. Nevertheless, the use of a fixed cooling temperature in this study is reasonable given that the subject population is largely homogenous and has been exposed to standardized environmental conditions.

This study supports the combination of IRT with WBC to study BAT activation under cold air exposure. This process improves the semi-automated detection of anatomically appropriate ROIs and the progressive analysis of spatially corrected thermal images collected in a time series. The resultant output provides reliable estimates on the degree of activation of BAT over time for each subject, which may then be correlated with EE data to confirm non-shivering thermogenesis. Future work will focus on further automation in IRT to assess BAT metabolic activity in diverse subjects and populations, so as to allow reliable and reproducible measurements in clinical trials exploring the therapeutic targeting of BAT in treating metabolic disorders.

\section{Authors' contributions}

S. H. Tay and M. K. S. Leow conceived and executed the study, as well as participated in data analysis and in the writing of the manuscript. H. J. Goh, P. Govindharajulu,
J. Cheng, S. G. Camps and Y. Q. Li participated in the experimentation and data analysis, and contributed to the review of the manuscript. S. Haldar, S. S. Velan, L. Sun and C. J. Henry provided intellectual input and critically reviewed the manuscript.

\section{Availability of data and materials}

All data generated or analyzed during this study are included in this published article. The datasets used and/or analyzed during the current study are available from the corresponding author on reasonable request.

\section{Conflict of Interest}

There is no conflict of interest.

\section{Acknowledgements}

Funding for the study was obtained from core funding provided by the Agency of Science, Technology and Research (A*STAR), Singapore. We would like to thank Ms. S. Poh Suan Lim for her expertise in phlebotomy and SICS (A*STAR) for generous laboratory funding support for this study. We also thank Dr. F. Meng for his assistance with the Monte Carlo simulation.

\section{References}

ACOSTA FM, MARTINEZ-TELLEZ B, SANCHEZ-DELGADO G, ALCANTARA JMA, ACOSTA-MANZANO P, MORALES-ARTACHO AJ, RUIZ JR: Physiological responses to acute cold exposure in young lean men. PLoS One 13: e0196543, 2018. https://doi.org/10.1371/journal.pone.0196543

ANG QY, GOH HJ, CAO Y, LI Y, CHAN SP, SWAIN JL, HENRY CJ, LEOW MKS: A new method of infrared thermography for quantification of brown adipose tissue activation in healthy adults (TACTICAL): a randomized trial. J Physiol Sci 67: 395-406, 2017. https://doi.org/10.1007/s12576-016-0472-1

BI X, LOO YT, HENRY CJ: Body fat measurements in Singaporean adults using four methods. Nutrients 10: pii: E303, 2018. https://doi.org/10.3390/nu10030303

BOON MR, BAKKER LEH, VAN DER LINDEN RAD, PEREIRA ARIAS-BOUDA L, SMIT F, VERBERNE HJ, VAN MARKEN LICHTENBELT WD, JAZET IM, RENSEN PCN: Supraclavicular skin temperature as a measure of18F-FDG uptake by BAT in human subjects. PLoS One 9: e98822, 2014. https://doi.org/10.1371/journal.pone.0098822

BOON MR, VAN MARKEN LICHTENBELT WD: Brown Adipose Tissue: A Human Perspective. Handbook of Experimental Pharmacology Germany 233: 301-319, 2016. https://doi.org/10.1007/164_2015 11

CANNON B, NEDERGAARD J: Brown adipose tissue: function and physiological significance. Physiol Rev 84: 277-359, 2004. https://doi.org/10.1152/physrev.00015.2003

CARTER EA, BONAB AA, PAUL K, YERXA J, TOMPKINS RG, FISCHMAN AJ: Association of heat production with 18F-FDG accumulation in murine brown adipose tissue after stress. J Nucl Med 52: 1616-1620, 2011. https://doi.org/10.2967/jnumed.111.090175

CHEN YI, CYPESS AM, SASS C A, BROWNELL A-L, JOKIVARSI KT, KAHN CR, KWONG KK: Anatomical and functional assessment of brown adipose tissue by magnetic resonance imaging. Obesity 20: 1519-1526, 2012. https://doi.org/10.1038/oby.2012.22 
CHONDRONIKOLA M, VOLPI E, BORSHEIM E, CHAO T, PORTER C, ANNAMALAI P, YFANTI C, LABBE SM, HURREN NM, MALAGARIS I, CESANI F, SIDOSSIS LS: Brown adipose tissue is linked to a distinct thermoregulatory response to mild cold in people. Front Physiol 7: 129, 2016. https://doi.org/10.3389/fphys.2016.00129

CLERTE M, BARON DM, BROUCKAERT P, ERNANDE L, RAHER MJ, FLYNN AW, PICARD MH, BLOCH KD, BUYS ES, SCHERRER-CROSBIE M: Brown adipose tissue blood flow and mass in obesity: a contrast ultrasound study in mice. J Am Soc Echocardiogr 26: 1465-1473, 2013. https://doi.org/10.1016/j.echo.2013.07.015

CRANE JD, MOTTILLO EP, FARNCOMBE TH, MORRISON KM, STEINBERG GR: A standardized infrared imaging technique that specifically detects UCP1-mediated thermogenesis in vivo. Mol Metab 3: 490-494, 2014. https://doi.org/10.1016/j.molmet.2014.04.007

CYPESS AM, HAFT CR, LAUGHLIN MR, HU HH: Brown fat in humans: consensus points and experimental guidelines. Cell Metab 20: 408-415, 2014. https://doi.org/10.1016/j.cmet.2014.07.025

CYPESS AM, LEHMAN S, WILLIAMS G, TAL I, RODMAN D, GOLDFINE AB, KUO FC, PALMER EL, TSENG Y-H, DORIA A, KOLODNY GM, KAHN CR: Identification and importance of brown adipose tissue in adult humans. New England J Med 360: 1509-1517, 2009. https://doi.org/10.1056/NEJMoa0810780

FLYNN A, LI Q, PANAGIA M, ABDELBAKY A, MACNABB M, SAMIR A, CYPESS AM, WEYMAN AE, TAWAKOL A, SCHERRER-CROSBIE M: Contrast-enhanced ultrasound: a novel noninvasive, nonionizing method for the detection of brown adipose tissue in humans. J Am Soc Echocardiogr 28: 1247-1254, 2015. https://doi.org/10.1016/j.echo.2015.06.014

GAGGE AP, BURTON AC, BAZETT HC: A practical system of units for the description of the heat exchange of man with his environment. Science 94: 428-430, 1941. https://doi.org/10.1126/science.94.2445.428

GATIDIS S, SCHMIDT H, PFANNENBERG CA, NIKOLAOU K, SCHICK F, SCHWENZER NF: Is it possible to detect activated brown adipose tissue in humans using single-time-point infrared thermography under thermoneutral conditions? impact of bmi and subcutaneous adipose tissue thickness. PLoS One 11: e0151152, 2016. https://doi.org/10.1371/journal.pone.0151152

GESTA S, TSENG YH, KAHN CR: Developmental origin of fat: tracking obesity to its source. Cell 131: 242-256 2007. https://doi.org/10.1016/j.cell.2007.10.004

GOH HJ, GOVINDHARAJULU P, CAMPS SG, TAN SY, HENRY CJ: Gross and relative energy cost of domestic household activities in Asian men. Eur J Clin Nutr 70: 1414-1419, 2016. https://doi.org/10.1038/ejen.2016.134

GREENHILL C: Obesity: Cold exposure increases brown adipose tissue in humans. Nat Rev Endocrinol 9: 566, 2013. https://doi.org/10.1038/nrendo.2013.156

HAINER V, ZAMRAZILOVA H, KUNESOVA M, BENDLOVA B, ALDHOON-HAINEROVA I: Obesity and infection: reciprocal causality. Physiol Res 64 (Suppl 2): S105-S119, 2015.

HAQ T, CRANE JD, KANJI S, GUNN E, TARNOPOLSKY MA, GERSTEIN HC, STEINBERG GR, MORRISON KM: Optimizing the methodology for measuring supraclavicular skin temperature using infrared thermography; implications for measuring brown adipose tissue activity in humans. Sci Rep England 7: 11934, 2017. https://doi.org/10.1038/s41598-017-11537-X

HENRY CJ, KAUR B, QUEK RYC, CAMPS SG: A Low glycaemic index diet incorporating isomaltulose is associated with lower glycaemic response and variability, and promotes fat oxidation in asians. Nutrients 9: 473, 2017. https://doi.org/10.3390/nu9050473

HOYTE T, SCHIAVON S, PICCOLI A, MOON D, STEINFELD K: CBE Thermal Comfort Tool. Center for the Built Environment, University of California Berkeley, 2013, available at: http://cbe.berkeley.edu/comforttool/.

HU HH, PERKINS TG, CHIA JM, GILSANZ V: Characterization of human brown adipose tissue by chemical-shift water-fat MRI. AJR Am J Roentgenol 200: 177-183, 2013. https://doi.org/10.2214/AJR.12.8996

ISHIBASHI J, SEALE P: Medicine. Beige can be slimming. Science 328: 1113-1114, 2010. https://doi.org/10.1126/science.1190816

JANG C, JALAPU S, THUZAR M, LAW PW, JEAVONS S, BARCLAY JL, HO KKY: Infrared thermography in the detection of brown adipose tissue in humans. Physiol Rep 2: pii: e12167, 2014. https://doi.org/10.14814/phy2.12167 
LAU AZ, CHEN AP, GU Y, LADOUCEUR-WODZAK M, NAYAK KS, CUNNINGHAM CH: Noninvasive identification and assessment of functional brown adipose tissue in rodents using hyperpolarized $13 \mathrm{C}$ imaging. Int J Obes (London) 38: 126-131, 2014. https://doi.org/10.1038/ijo.2013.58

LAW J, MORRIS DE, IZZI-ENGBEAYA C, SALEM V, COELLO C, ROBINSON L, JAYASINGHE M, SCOTT R, GUNN R, RABINER E, TAN T, DHILLO WS, BLOOM S, BUDGE H, SYMONDS ME: thermal imaging is a noninvasive alternative to PET/CT for measurement of brown adipose tissue activity in humans. J Nucl Med 59: 516-522, 2018. https://doi.org/10.2967/jnumed.117.190546

LEE P, HO KKY, LEE P, GREENFIELD JR, HO KKY, GREENFIELD JR: Hot fat in a cool man: infrared thermography and brown adipose tissue. Diabetes Obes Metab 13: 92-93, 2011. https://doi.org/10.1111/j.14631326.2010.01318.x

LOWELL BB, SPIEGELMAN BM: Towards a molecular understanding of adaptive thermogenesis. Nature 404: 652-660, 2000. https://doi.org/10.1038/35007527

MASUDA Y, HARAMIZU S, OKI K, OHNUKI K, WATANABE T, YAZAWA S, KAWADA T, HASHIZUME S, FUSHIKI T: Upregulation of uncoupling proteins by oral administration of capsiate, a nonpungent capsaicin analog. J Appl Physiol (1985) 95: 2408-2415, 2003. https://doi.org/10.1152/japplphysiol.00828.2002

MORRISON SF: Central neural control of thermoregulation and brown adipose tissue. Auton Neurosci 196: 14-24, 2016. https://doi.org/10.1016/j.autneu.2016.02.010

PETROVIC N, WALDEN TB, SHABALINA IG, TIMMONS JA, CANNON B, NEDERGAARD J: Chronic peroxisome proliferator-activated receptor $\gamma(\operatorname{PPAR} \gamma)$ activation of epididymally derived white adipocyte cultures reveals a population of thermogenically competent, UCP1-containing adipocytes molecularly distinct from classic brown adipocytes. J Biol Chem 285: 7153-7164, 2010. https://doi.org/10.1074/jbc.M109.053942

PITHA J, KOVAR J, BLAHOVA T: Fasting and nonfasting triglycerides in cardiovascular and other diseases. Physiol Res 64 (Suppl 3): S323-S330, 2015.

SACKS H, SYMONDS ME: Anatomical locations of human brown adipose tissue: functional relevance and implications in obesity and type 2 diabetes. Diabetes 62: 1783-1790, 2013. https://doi.org/10.2337/db12-1430

SAITO M, OKAMATSU-OGURA Y, MATSUSHITA M, WATANABE K, YONESHIRO T, NIO-KOBAYASHI J, IWANAGA T, MIYAGAWA M, KAMEYA T, NAKADA K, KAWAI Y, TSUJISAKI M: High incidence of metabolically active brown adipose tissue in healthy adult humans: effects of cold exposure and adiposity. Diabetes 58: 1526-1531, 2009. https://doi.org/10.2337/db09-0530

SAITO M, YONESHIRO T: Capsinoids and related food ingredients activating brown fat thermogenesis and reducing body fat in humans. Curr Opin Lipidol 24: 71-77, 2013. https://doi.org/10.1097/MOL.0b013e32835a4f40

SALEM V, IZZI-ENGBEAYA C, COELLO C, THOMAS DB, CHAMBERS ES, COMNINOS AN, BUCKLEY A, WIN Z, AL-NAHHAS A, RABINER EA, GUNN RN, BUDGE H, SYMONDS ME, BLOOM SR, TAN TM, DHILLO WS: Glucagon increases energy expenditure independently of brown adipose tissue activation in humans. Diabetes Obes Metab 18: 72-81, 2016. https://doi.org/10.1111/dom.12585

SOILlE P: Morphological Image Analysis: Principles and Applications. 1999. https://doi.org/10.1007/978-3-662$\underline{05088-0}$

SYMONDS ME, HENDERSON K, ELVIDGE L, BOSMAN C, SHARKEY D, PERKINS AC, BUDGE H: Thermal imaging to assess age-related changes of skin temperature within the supraclavicular region co-locating with brown adipose tissue in healthy children. J Pediatr 161: 892-898, 2012. https://doi.org/10.1016/j.jpeds.2012.04.056

VAN DER LANS AAJJ, VOSSELMAN MJ, HANSSEN MJW, BRANS B, VAN MARKEN LICHTENBELT WD: Supraclavicular skin temperature and BAT activity in lean healthy adults. J Physiol Sci 66: 77-83, 2016. https://doi.org/10.1007/s12576-015-0398-z

VAN MARKEN LICHTENBELT WD, VANHOMMERIG JW, SMULDERS NM, DROSSAERTS JMAFL, KEMERINK GJ, BOUVY ND, SCHRAUWEN P, TEULE GJJ: Cold-activated brown adipose tissue in healthy men. New Engl J Med 360: 1500-1508, 2009. https://doi.org/10.1056/NEJMoa0808718 
VEGIOPOULOS A, MÜLLER-DECKER K, STRZODA D, SCHMITT I, CHICHELNITSKIY E, OSTERTAG A, BERRIEL DIAZ M, ROZMAN J, HRABE DE ANGELIS M, NÜSING RM, MEYER CW, WAHLI W, KLINGENSPOR M, HERZIG S: Cyclooxygenase-2 controls energy homeostasis in mice by de novo recruitment of brown adipocytes. Science 328: 1158-1161, 2010. https://doi.org/10.1126/science.1186034

VIRTANEN KA, LIDELL ME, ORAVA J, HEGLIND M, WESTERGREN R, NIEM T, TAITTONEN M, LAINE J, SAVISTO NJ, ENERBÄCK S, NUUTILA P: Functional brown adipose tissue in healthy adults. New Engl J Med 360: 1518-1525, 2009. https://doi.org/10.1056/NEJMoa0808949

WALDÉN TB, HANSEN IR, TIMMONS JA, CANNON B, NEDERGAARD J: Recruited vs. nonrecruited molecular signatures of brown, "brite," and white adipose tissues. Am J Physiol Endocrinol Metab 302: E19-E31, 2012. https://doi.org/10.1152/ajpendo.00249.2011

ZHANG J, WU H, MA S, JING F, YU C, GAO L, ZHAO J: Transcription regulators and hormones involved in the development of brown fat and white fat browning: transcriptional and hormonal control of brown/beige fat development. Physiol Res 67: 347-362, 2018. https://doi.org/10.33549/physiolres. 933650 